\title{
REFORÇO EM LAJES DE CONCRETO ARMADO
}

\section{STRENGTHENING OF SOLID REINFORCED CONCRETE SLABS}

\author{
Carlos de Oliveira Campos ${ }^{1}$, Adilson Pereira da Rocha ${ }^{2}$, Ronaldo Barros Gomes ${ }^{3}$, Guilherme Sales Melo ${ }^{4}$
}

Recebido em 29 de agosto de 2012; recebido para revisão em 05 de setembro de 2012; aceito em 08 de setembro de 2012; disponível on-line em 19 de setembro de 2012.

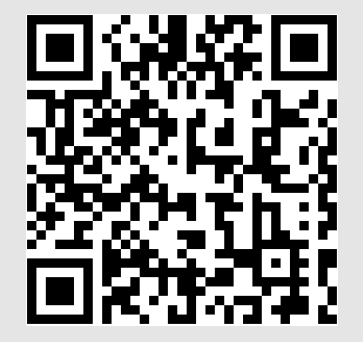

PALAVRAS CHAVES:

Laje;

Concreto armado;

Reforço.

\section{KEYWORDS:}

Slab;

Reinforced Concrete;

Strengthening.
RESUMO: Este trabalho aborda ensaios de lajes maciças de concreto armado, reforçadas pela face superior. Foram ensaiadas 5 lajes maciças de concreto armado, com dimensões de $415 \mathrm{~cm} \times 415 \mathrm{~cm} \times 7 \mathrm{~cm}$. As principais variáveis foram dois tipos de patologias comuns neste tipo de estrutura: deficiência da resistência do concreto e deficiência de armadura. A laje L1, de referência, foi ensaiada até a ruptura e as demais foram ensaiadas até um determinado limite de carregamento quando foram reforçadas e reensaiadas até a ruptura. Todas as lajes romperam por flexão e nas lajes armadas originalmente com uma taxa mínima de armadura, a aplicação da camada de reforço elevou em até $30 \%$ a carga de ruptura em relação a uma laje similar sem reforço, independentemente da resistência original do concreto. Em todos os ensaios das lajes reforçadas não se detectou descolamentos ou evidências de perda de aderência entre o concreto antigo e o concreto da camada de reforço.

ABSTRACT: This work discusses the tests results of solid reinforced concrete slabs, featuring a strengthened upper surface. Five solid reinforced concrete slabs were cast and tested, measuring $415 \mathrm{~cm} \times 415 \mathrm{~cm} \times 7 \mathrm{~cm}$. The main variables were two types of common pathologies in this kind of structure, namely, concrete strength and reinforcement deficiencies. Reference slab L1 was tested up to failure and the others were tested until a determined load, after which they were strengthened and retested up to failure. All slabs experienced flexural failure and in the slabs that were originally minimally reinforced, the application of the strengthening layer raised the failure load by up to $30 \%$ in relation to a similar unstrengthen slab, regardless of the original concrete strength. In all tests with strengthened slabs there were neither traces of bond failure nor evidence of loss of bond between the old concrete and the concrete of the strengthening layer.

\footnotetext{
* Contato com os autores:

${ }^{1}$ e-mail : cc@carloscampos.com.br (C. de O. Campos)

Eng. Civil MSc. - Carlos Campos Consultoria e Construções Limitada

2 e-mail : cc@carloscampos.com.br (A. P. da Rocha)

Eng. Civil MSc. - Carlos Campos Consultoria e Construções Limitada

3 e-mail : rbggomes@gmail.com (R. B. Gomes)

Prof. Dr. da Escola de Engenharia Civil - Universidade Federal de Goiás - UFG.

${ }^{4}$ e-mail : melog@unb.br (G. S. Melo)

Prof. Dr. do Departamento de Engenharia Civil e Ambiental da Universidade de Brasília - UnB.
}

\section{INTRODUÇÃO}

A recuperação estrutural no Brasil está inserida na própria história da construção civil. A engenharia tem sido ensinada desde a criação da Real Academia de Artilharia, Fortificação e Desenho, em 1792. Antes, os engenheiros militares e os "mestres de riscos" (do verbo riscar) já davam soluções técnicas de caráter "prático" e respostas aos problemas de fortificações, pontes e estradas na colônia de Portugal (AIDAR \& CITRYNOWICZ, 1993). As primeiras obras foram as estradas para tropas de mulas e carros de bois: ligando o Rio de Janeiro a Minas Gerais, passando pela Serra do Mar (1702); 
ligando Cubatão a São Bernardo do Campo (1740), estrada ampliada ou recuperada, ainda manualmente (1900), conforme mostra a Figura 1 e depois vieram as ferrovias que se expandiram durante o ciclo do café. Atingiu-se, 200 anos depois destas obras pioneiras, no início do século 20 , a maciça industrialização do país com as primeiras produções de 16 mil toneladas de laminados de aço e 60 mil toneladas de cimento, em 1926 (AIDAR \& CITRYNOWICZ, 1993).

Com a publicação em 1933 do "Boletim número

1 do Laboratório de Ensaios e Materiais da Escola Polythecnica de São Paulo", foram estabelecidas no Brasil as bases da tecnologia do "cimento armado", o que facilitou e possibilitou o surgimento de nossos primeiros "arranha-céus" no Rio e em São Paulo (Edifício Guinle, o pioneiro, IBRACON, 1992). No "Boletim número 1", o Prof. Ari Torres divulgava pesquisas realizadas em 1927, apenas oito anos após a publicação dos estudos de Abrams nos Estados Unidos sobre as relações entre o fator água/cimento e a resistência do concreto (AGOPYAN, 1993).

No período pós-guerra, 1950, começaram a ser introduzido no Brasil o uso do "aço especial" como era chamado o aço CAT 50 e CAT 60 e as primeiras obras projetadas com concreto protendido. Os edifícios, pontes e viadutos construídos até aquela época, sem o uso destes novos materiais e técnicas, em uma parte deles até hoje não apresentaram grandes problemas, tanto de natureza estrutural quanto de corrosão. No início dos anos 60 começaram a aparecer os problemas, geralmente associados a fenômenos de corrosão, período logo após a introdução destas inovações.

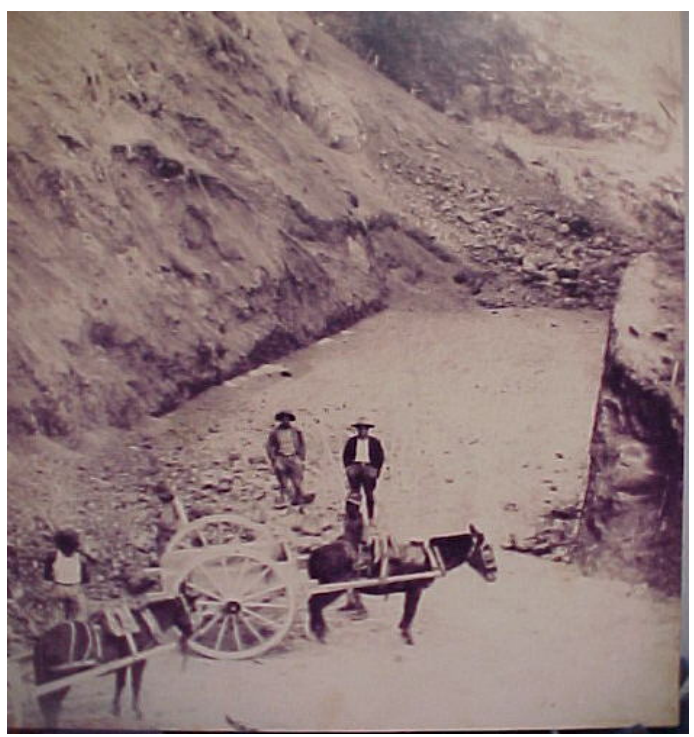

Figura 1: Reforma e ampliação do trecho de Cubatão a São Bernardo do Campo. Queda de barreiras em uma "cava" manual com transporte do material em carroças de burros (fotografia cedida pela empresa (BPO).
Na década de 60, com tecnologia importada dos Estados Unidos, surgiu no Rio de Janeiro a empresa de recuperação Jatocret, que ocupou uma lacuna existente no mercado e difundiu entre nós o uso do concreto projetado. Essa empresa, já na década de 80, tinha filiais em quase todas as capitais brasileiras, mas na década de 90 desapareceu do cenário juntamente com outras empresas de engenharia de âmbito nacional. O concreto projetado, também conhecido como GUNITE (um anglicismo devido ao bico de projeção ser também chamado de canhão (gun) de projeção), segundo o engenheiro Sérgio Gonçalves Ferreira, presidente da Jatocret. "... é a técnica mais recomendada na recuperação e reforços de lajes". O próprio Ferreira continua “... faz com que seja indicado e é praticamente o único, no reforço de lajes, na parte inferior". A Jatocret, pioneira deste segmento, fornecia exemplos de sucesso, principalmente na mídia e em congressos de engenharia, mostrando recuperações espetaculares, principalmente em sinistros de incêndio, como as do Museu de Arte Moderna do Rio, do Edifício Andrauss e do Edifício Joelma em São Paulo. As indústrias nacionais passaram a fabricar as máquinas para produção deste concreto, como a Este Industrial, que desde 1978 fabrica o equipamento.

Assim poderia ser descrito o cenário nacional de recuperações. O concreto projetado era uma técnica de vanguarda para recuperação estrutural e era aplicado em praticamente todas as situações. $O$ argumento servia para garantir à Jatocret a exclusividade e as principais obras de recuperação no Brasil. Principalmente como consequência do trabalho da Jatocret, o Brasil, desde o final da década de 60, passou a ser um dos maiores aplicadores de concreto projetado no mundo como material de recuperação estrutural, a par dos Estados Unidos, onde foi patenteado em 1908 (SOUZA e RIPPER, 1998). Salientase que o concreto projetado, que pode ser do tipo "via seca" ou "via úmida", é de difícil aplicação. O operador, "mangoteiro", fica imerso num ambiente empoeirado e muitas vezes com o uso de roupas pressurizadas e sujeito aos ricochetes dos agregados durante a aplicação, ou ainda sujeito ao contato com o pó dos aditivos que contêm produtos cáusticos ou irritantes em contato com a pele, no caso, os aceleradores de pega. $O$ Engenheiro Epaminondas Melo do Amaral Filho, em 1987, comentava sobre a dificuldade de aplicação do produto: "Um bico de projeção ruim na mão de um profissional muito bom não tem seu desempenho comprometido; mas um excelente equipamento, manipulado por um trabalhador ineficiente, não funciona". Na mesma entrevista, Amaral Filho já 
recomendava o uso de microssílica, com teores de $10 \%$ a $12 \%$ em relação à massa de cimento, para melhorar o concreto projetado, evitando ou diminuindo o ricochete e aumentando consideravelmente a impermeabilidade (Revista Dirigente Construtor, 1987).

Ao longo dos anos a grande demanda pelo uso do concreto armado permitiu o aparecimento de diversos problemas na construção civil devidos à execução, ao desempenho dos materiais e, em muitos casos, pela falta de manutenção. Dentre os problemas mais frequentes em peças de concreto armado, podemse ressaltar os ocorridos em lajes, com manifestações de grandes flechas e aparecimento de fissuras. Os problemas em lajes causados por insuficiência na taxa de armadura ou uso de um concreto inadequado podem restringir sua utilização eventualmente necessitando a execução de um reforço.

O reforço com concreto armado envolve diferentes aspectos, tais como, a escolha dos tipos de cimento, granulometrias de agregados e classes de aços mais adequados para serem utilizados na intervenção. Podem envolver processos de preparações especiais para colagem e verificação de compatibilidades entre solicitações e deformações dos materiais. Toda decisão deve ser balizada no diagnóstico que pode ser de caráter estrutural, de ações que envolvem processos de corrosão de armaduras ou de sinistros.

No caso de reforço com alguma forma de adição de concreto, a superfície que vai receber novo concreto deve se apresentar com alguma rugosidade e deve estar limpa. É necessário retirar a nata de cimento por causa das baixas resistências de sua aderência ao concreto. As formas de preparo superficial vão desde os marteletes elétricos ou pneumáticos até o apicoamento manual, as fresadoras mecânicas, equipamentos de hidro demolição de altíssima pressão $(75,0 \mathrm{MPa})$ e eventualmente o jato de areia seco ou úmido. $O$ reforço de uma peça que implique no acréscimo de um novo volume de concreto à peça antiga, deve proporcionar uma monoliticidade tal que faça com que os concretos novo e antigo trabalhem juntos.

Diversas são as alternativas de reforço, e sua aplicação depende de vários fatores entre os quais se deve citar como um dos preponderantes, a determinação da causa efetiva da patologia. Uma grande vantagem do concreto projetado no reforço estrutural é a rapidez por dispensar o uso de formas. Em razão da qualidade superior, pela facilidade de controle dos processos e materiais, o microconcreto fluido, também denominado "graute", é um material muito indicado nos serviços de reforço estrutural. O reforço com "graute", produto à base de cimento, implica superfície rugosa e saturada. Um reforço com materiais colados pode ser suscetível às variações de temperatura. Geralmente nas colagens são usadas colas orgânicas, eventualmente suscetíveis a altas temperaturas. $\mathrm{Na}$ colagem das chapas metálicas pode-se usar o artifício da fixação com parafusos. No reforço com colagem de fibra de carbono devem ser tomados cuidados para se evitar o comprometimento da ductilidade da peça e, em virtude da pouca espessura do produto do reforço, apresenta a vantagem da facilidade de aplicação da camada de proteção.

O reforço em laje pela face superior prevê a aplicação de uma camada de concreto de alto desempenho com espessura variável. Esta variação na espessura confere à camada de reforço uma forma de lente plano-convexa de bordos delgados, pequena espessura nos bordos e espessuras maiores no centro, calculada levando em conta o vão, taxa de armadura e solicitações.

\section{OBJETIVO}

Este trabalho tem por objetivo verificar e analisar o comportamento estrutural de lajes de concreto armado reforçadas na face superior, através de ensaios em peças moldadas em escala real. Enfoca a eficiência do processo de reforço diante de duas patologias mais frequentes em lajes que são as deficiências: da taxa de armadura e da resistência à compressão do concreto (CAMPOS, 2000).

\section{METODOLOGIA}

Com o objetivo de analisar o comportamento estrutural de lajes maciças de concreto armado reforçadas pelo bordo superior, foram ensaiados à flexão cinco modelos em escala real $(415 \mathrm{~cm} \times 415 \mathrm{~cm} \times$ $7 \mathrm{~cm}$ ). As lajes, simplesmente apoiadas e carregadas uniformemente no bordo superior, foram armadas nas duas direções e dimensionadas de acordo com a NBR $6118 / 80$, com sobrecargas recomendadas para usos residenciais de $1,5 \mathrm{kN} / \mathrm{m}^{2}$. As principais variáveis de ensaio foram taxa de armadura, $\rho(0,076 \%$ e 0,164 \%), e a resistência à compressão do concreto, $f_{c}(10 \mathrm{MPa}$ e $20 \mathrm{MPa})$.

A laje $L 1$, de referência, foi ensaiada até a ruptura em um único ensaio. A laje $L 2$ foi construída idêntica a L1, e as lajes L3 e L4 foram concretadas de forma a simular a existência das seguintes patologias: uma com deficiência da armadura ( $L 3, \rho=0,076 \%$ ) e outra com deficiência da resistência do concreto ( $L 4$, $\mathrm{f}_{\mathrm{c}}=10 \mathrm{MPa}$ ). Foi construída uma laje adicional, L3a, que substituiu a laje L3 em função de sua ruptura no ensaio 
inicial. As lajes, L2, L3, L3a e L4, foram ensaiadas inicialmente até o carregamento limite de parada. 0 limite de parada do carregamento, definido para atingir um estado caracterizado por intensa fissuração e grandes deslocamentos, teve por base três parâmetros: a) deformação, na armadura principal, atingindo o limite de escoamento; b) abertura das fissuras com limites estabelecidas em norma e; c) flechas com a ordem de grandeza da espessura da laje. Após este ponto, com exceção da L3 que rompeu, as lajes foram descarregadas, reforçadas e ensaiadas até a ruptura.

O reforço foi realizado com aplicação de uma camada, em forma de lente, na face superior da laje, de concreto de alto desempenho, com espessuras de 2,0 $\mathrm{cm}$ nos bordos e $4,0 \mathrm{~cm}$ no centro. Em todas as lajes reforçadas, renomeadas de $L 2 R$, L3aR e L4R, o tipo do concreto utilizado no reforço e as dimensões da camada foram mantidos constantes. A Tabela 1 apresenta as principais variáveis dos modelos em teste, o programa de ensaios iniciais executados até a uma parada de carregamento programada e os ensaios executados até a ruptura. A Figura 2 apresenta as dimensões nominais e detalhamento das armaduras das lajes.

O concreto utilizado na confecção das lajes L1, L2, L3 e L3a tinha resistência nominal à compressão prevista aos 21 dias de $20 \mathrm{MPa}$. O concreto da laje L4 foi moldado no local, com traço previamente estudado e expectativa de resistência à compressão, aos 21 dias, de 10,0 MPa. A Tabela 2 apresenta a composição do concreto usado nas lajes. O concreto foi lançado na forma, adensado com vibradores de imersão e desempenado manualmente. Após cerca de duas horas, as lajes foram cobertas com sacos de aniagem úmidos e recobertos com lona de polietileno para conservação da umidade e mantidos nestas condições por 7 dias. Em todas as concretagens foram moldados dez corpos-deprova cilíndricos de $150 \mathrm{~mm} \mathrm{X} 300 \mathrm{~mm}$ para caracterização do material.

Tabela 1: Programa de ensaios e principais variáveis das lajes ensaiadas.

\begin{tabular}{c|c|c|c|c} 
Laje & $\rho(\%)$ & $\mathbf{f}_{\mathrm{c}}(\mathrm{MPa})$ & Ensaio inicial & $\begin{array}{c}\text { Ensaio até } \\
\text { ruptura }\end{array}$ \\
\hline $\mathrm{L} 1$ & 0,164 & 20 & - & Ruptura \\
\hline $\mathrm{L} 2$ & 0,164 & 20 & Parada programada & Ruptura (L2R) \\
\hline L3 & 0,076 & 20 & Ruptura $*$ & \\
\hline L3a & 0,076 & 20 & Parada programada & Ruptura (L3aR) \\
\hline L4 & 0,164 & 10 & Parada programada & Ruptura (L4R) \\
\hline
\end{tabular}

* - Ruptura com carregamento aquém do previsto.

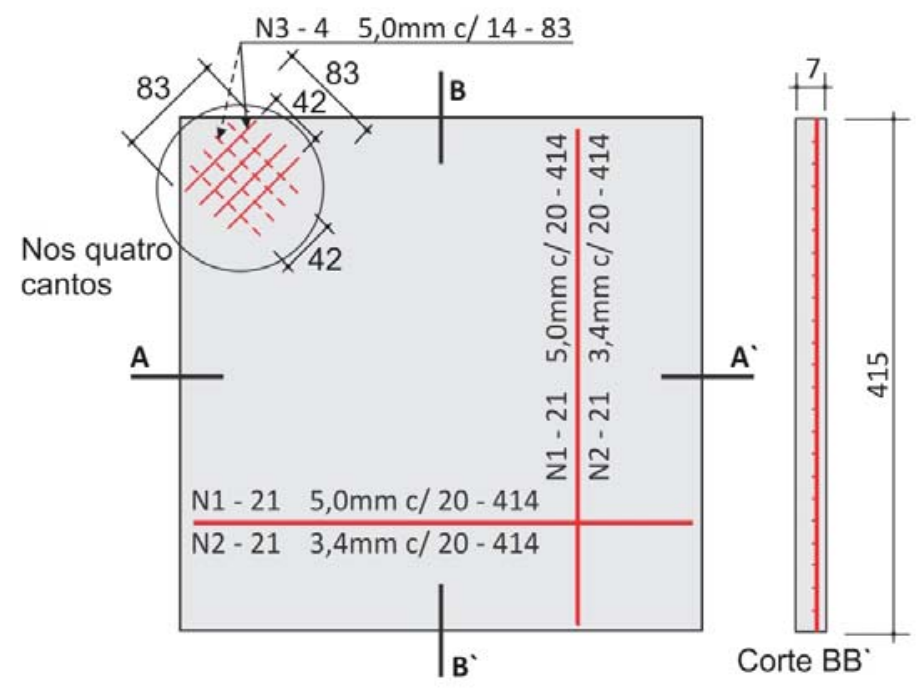

Un.: cm

Ferragem na Borda Inferior -..- Ferragem na Borda Superior N1 - Lajes L1, L2 e L4 N2 - Laje L3 e L3a N3 - Lajes L1, L2, L3, L3a e L4

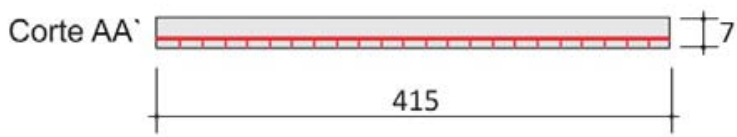

Figura 2: Dimensões das lajes e detalhamento das armaduras. 
A instrumentação das lajes nos ensaios foi feita com deflectômetros mecânicos, analógicos, para medição dos deslocamentos verticais, e extensômetros elétricos de resistência para medição das deformações no aço e no concreto. Em todos os ensaios, exceto no ensaio da laje L1, foi utilizada uma trena metálica, posicionada no centro da laje (face inferior), com a finalidade de visualizar melhor os deslocamentos verticais. Apesar de o uso da trena não propiciar medidas com o mesmo grau de precisão, serviram para obtenção aproximada da flecha central na ruptura, após a retirada dos deflectômetros mecânicos.

Foram utilizados, em cada laje, no mínimo cinco deflectômetros da marca "Mitutoyo", com precisão de $0,01 \mathrm{~mm}$, posicionados na superfície inferior. Devido à simetria, as flechas foram medidas em apenas um quadrante, utilizando-se os aparelhos posicionados no eixo central e na diagonal das lajes. Também foram fixados, na armadura principal de flexão, extensômetros elétricos do tipo KLM PA 06 250BA 120L da "Kiowa", em 12 pontos de cada laje. Nas lajes L1 e L2 foram utilizados dois extensômetros por ponto, diametralmente opostos, nos lados inferior e superior da armadura. Nas demais lajes utilizou-se apenas um extensômetro por ponto, fixado no lado inferior da armadura. Na superfície do concreto, na face superior de todas as lajes, foram colados extensômetros elétricos, do tipo KLM PA 06 201BA 120L da "Kiowa", em quatro pontos, para determinação das deformações. A Figura 3 apresenta a posição dos deflectômetros usados e dos extensômetros elétricos fixados tanto nas armaduras de flexão quanto na superfície do concreto das lajes.

A laje L1 foi carregada com sacos de areia de $0,50 \mathrm{kN}$ e as demais lajes foram carregadas com sacos de 0,25 kN. Inicialmente cada laje foi marcada em 16 quadros de um metro quadrado. Cada etapa de carregamento ocupava um quadrante destes quadros. A sequência de colocação dos sacos seguiu a orientação previamente estabelecida de posicionar os sacos do centro para os bordos, conforme esquema apresentado no desenho da Figura 4. Para evitar o "efeito de arco" no carregamento, os sacos se tocavam apenas no interior de cada um dos 16 quadros. A confecção do reforço foi igual para as lajes reforçadas, L2R, L3aR e L4R. Inicialmente fez-se o apicoamento manual na face superior, com ponteiro e martelo, criando-se uma superfície rugosa e sem nata de cimento.

A Figura 5 mostra fotografia da execução do serviço de apicoamento manual. A superfície apicoada foi lavada com água através de bomba de alta pressão para remoção de todo pó e areia solta. Com o uso de macaco hidráulico, as lajes foram retornadas à sua forma plana original, no momento no início dos ensaios. Esta operação foi controlada por linha esticada na face superior fixada no centro das laterais e com nivelamento feito usando um nível ótico (NA K1 - WILD). O reforço foi realizado com aplicação de uma camada, em forma de lente, na face superior da laje, de concreto de alto desempenho, com espessuras de $2,0 \mathrm{~cm}$ nos bordos e $4,0 \mathrm{~cm}$ no centro. A Figura 6 apresenta a fotografia do carregamento total da laje L4R (após reforço), com 12 camadas e as quatro pilhas em cada quadro sem tocar as pilhas dos quadros vizinhos.

O concreto de alto desempenho utilizado para o reforço foi o mesmo para as três lajes reforçadas. Imediatamente após aplicação e acabamento da camada de reforço, ainda com o concreto fresco, a laje foi recoberta com mantas de aniagem úmidas e protegidas com lona de polietileno, e mantida nestas condições para cura, durante sete dias. A Tabela 3 apresenta o traço do concreto utilizado no reforço.

\begin{tabular}{c|c|c}
\multicolumn{4}{c}{ Tabela 2: Composição do concreto usado nas lajes. } \\
\hline MATERIAIS $\left(\mathrm{kg} / \mathrm{m}^{3}\right.$ ) & L1, L2, L3 e L3a & L4 \\
\hline Cimento (CP II F -32 ) & 297 & 240 \\
\hline Areia artificial (granulito) & 861 & 868 \\
\hline Brita zero (granulito) & -- & 197 \\
\hline Brita 1 & 960 & 782 \\
\hline Água & 172 & 195 \\
\hline Plast./Retardador REAX RX 104 R & 0,89 & - \\
\hline Traço unitário (em massa) & $1: 2,90: 3,23: 0,58$ & $1: 3,62: 0,82: 3,26: 0,81$ \\
\hline Expectativa de resistência & $\mathrm{f}_{\mathrm{c} 21}=20,0 \mathrm{MPa}$ & $\mathrm{f}_{\mathrm{c} 21}=10,0 \mathrm{MPa}$ \\
\hline
\end{tabular}




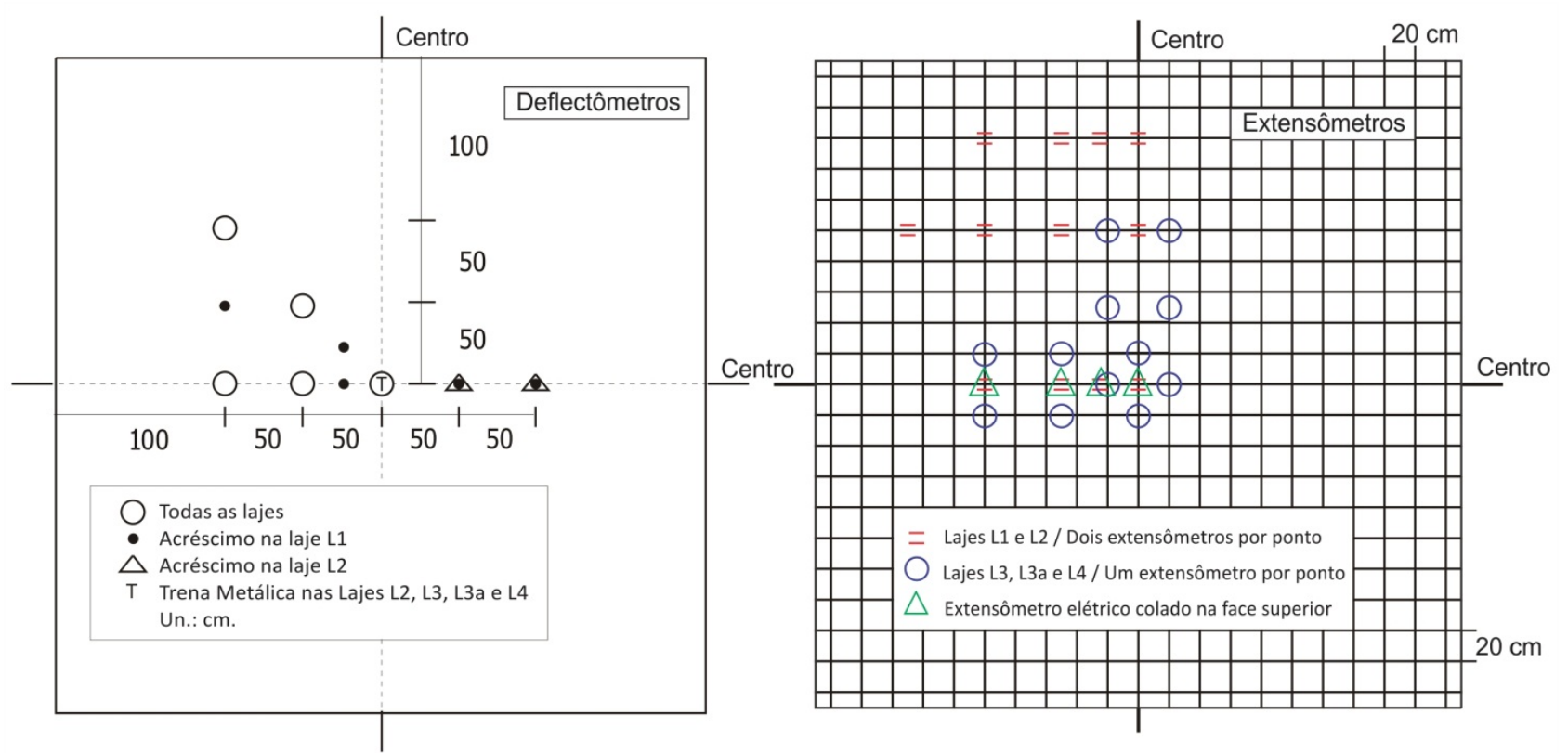

Figura 3: Posição dos deflectômetros usados e dos extensômetros elétricos fixados tanto nas armaduras de flexão quanto na superfície do concreto das lajes.

\begin{tabular}{|c|c||c:c||c:c||c:c|}
\hline 13 & 45 & 12 & 44 & 11 & 43 & 10 & 42 \\
\hline 61 & 29 & 60 & 28 & 59 & 27 & 58 & 26 \\
\hline \hline 14 & 46 & 3 & 35 & $\mathbf{2}$ & 34 & $\mathbf{9}$ & 41 \\
\hdashline 62 & 30 & 51 & 19 & 50 & 18 & 57 & 25 \\
\hline \hline 15 & 47 & $\mathbf{4}$ & 36 & 1 & 33 & $\mathbf{8}$ & 40 \\
\hline 63 & 31 & 52 & 20 & 49 & 17 & 56 & 24 \\
\hline \hline 16 & 48 & $\mathbf{5}$ & 37 & $\mathbf{6}$ & 38 & $\mathbf{7}$ & 39 \\
\hdashline 64 & 32 & 53 & 21 & 54 & 22 & 55 & 23 \\
\hline
\end{tabular}

Figura 4: Esquema da sequência de colocação dos sacos.

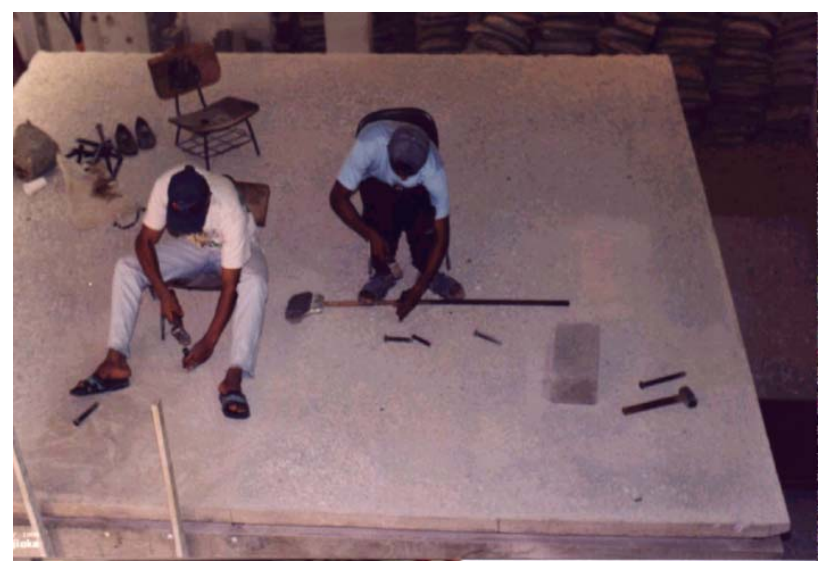

Figura 5: Fotografias da execução do apicoamento manual.

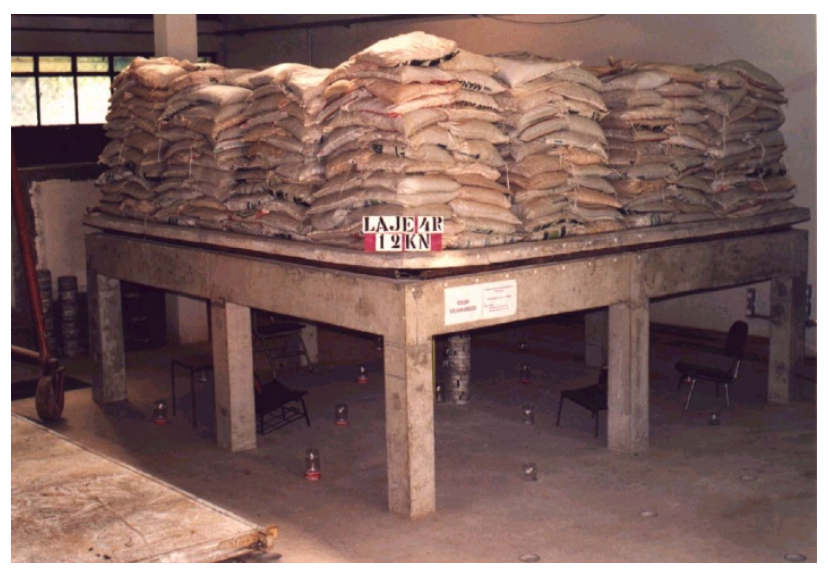

Figura 6: Fotografia da laje L4R com carregamento de $12,0 \mathrm{kN} / \mathrm{m}^{2}$ 


\section{RESULTADOS}

São apresentados os resultados de caracterização dos materiais empregados na confecção dos modelos estudados, cargas e modos de ruptura, fissuração, deslocamentos verticais e deformações no aço e no concreto. Também são mostrados os resultados e considerações sobre aderência entre o concreto antigo da laje e o concreto da camada de reforço.

O concreto utilizado na confecção das lajes L1, L2, L3 e L3a foi adquirido de empresa fornecedora de concreto pré-misturado, com uma previsão de resistência à compressão, para 21 dias, de $20 \mathrm{MPa}$. $\mathrm{O}$ concreto da laje $\mathrm{L} 4$ com a resistência à compressão prevista para $10 \mathrm{MPa}$, aos 21 dias, foi elaborado no Laboratório de Estruturas - EEC/UFG, seguindo o traço previamente estudado. O concreto utilizado no reforço das lajes L2R, L3aR e L4R foi preparado no local de concretagem das lajes, seguindo traço previamente estudado. A Tabela 4 apresenta as características do concreto de todas as lajes.

Tabela 3: Composição do concreto usado no reforço das lajes.

\begin{tabular}{c|c} 
MATERIAIS (kg) & L2R, L3aR e L4R \\
\hline Cimento (CP V - ARI) & 50,0 \\
\hline Areia artificial (granulito) & 37,5 \\
\hline Brita zero (granulito) & 72,5 \\
\hline Sílica ativa (SILMIX) & 4.0 \\
\hline Água (litros) & 20 \\
\hline Superplastificante (RX 3000A) & 0,7 \\
\hline Traço unitário (em massa) & $1: 0,75: 1,45: 0,37$ \\
\hline Expectativa de resistência & $\mathrm{f}_{\mathrm{c} 7}=50,0 \mathrm{MPa}$ \\
\hline
\end{tabular}

Tabela 4: Características do concreto utilizado nas lajes.

Concreto do substrato

\begin{tabular}{|c|c|c|c|c|}
\hline LAJE & Idade (dias) & $\mathrm{f}_{\mathrm{c}}{ }^{(1)}(\mathrm{MPa})$ & $\mathrm{f}_{\mathrm{c}}{ }^{(2)}$ (MPa) & $E_{c}^{(3)}(G P a)$ \\
\hline L1 & 18 & 17,0 & 20,8 & 16,1 \\
\hline L2 & 21 & 17,6 & 20,7 & 17,1 \\
\hline L3 & 21 & 17,0 & 20,4 & 17,3 \\
\hline L3a & 30 & 16,0 & 19,8 & 16,5 \\
\hline L4 & 17 & 9,6 & 12,4 & 15,7 \\
\hline \multicolumn{5}{|c|}{ Concreto utilizado no reforço } \\
\hline L2R & 16 & 44,9 & 51,9 & 36,0 \\
\hline L3aR & 17 & 51,9 & 58,2 & 32,0 \\
\hline L4R & 11 & 48,7 & 56,4 & 30,7 \\
\hline \multicolumn{5}{|c|}{$\begin{array}{l}\text { (1) Resistência à compressão cilíndrica do concreto aos } 7 \text { dias. } \\
\text { (2) Resistência à compressão cilíndrica do concreto no dia do ensaio da laje. } \\
\text { (3) Módulo de Elasticidade do concreto na data do ensaio da laje. }\end{array}$} \\
\hline
\end{tabular}


Foram ensaiadas à tração axial, no mínimo, duas amostras por laje das armaduras de flexão, com a finalidade de determinar as resistências de escoamento e de ruptura, módulo de elasticidade e a deformação específica de acordo com a NBR 6152 /80. Em todos os ensaios as barras não apresentaram patamar de escoamento definido e a Tabela 5 mostra os principais resultados de caracterização do aço.

A laje L1, de referência, rompeu com um carregamento de $9,25 \mathrm{kN} / \mathrm{m}^{2}$. As demais lajes, com exceção da $L 3$, foram ensaiadas no primeiro ensaio até o carregamento de parada. As lajes L2 (20,8 MPa) e L4 $(12,4 \mathrm{MPa})$, com taxas de armadura de $0,15 \%$ e $0,16 \%$, respectivamente, tiveram cargas de parada de 6,50 $\mathrm{kN} / \mathrm{m}^{2}$ e $4,75 \mathrm{kN} / \mathrm{m}^{2}$. Com o objetivo de provocar a máxima deterioração possível e como estava prevista uma carga de parada na faixa de 2,75 a $3,25 \mathrm{kN} / \mathrm{m}^{2}$, a laje L3 foi carregada até $3,0 \mathrm{kN} / \mathrm{m}^{2}$, quando ocorreu a ruptura. Os resultados da laje L3 foram mantidos para efeito de comparação.
A laje L3a foi confeccionada em substituição da laje L3. Devido ao fato de o reforço ter sido feito em forma de lente e consequentemente ter apresentado alturas variáveis ao longo do plano da laje, a altura efetiva considerada foi medida na região de momentos máximos no centro das lajes. As cargas de ruptura das lajes L2R e L4R foram muito próximas entre si, com 12,25 $\mathrm{kN} / \mathrm{m}^{2}$ e $12,0 \mathrm{kN} / \mathrm{m}^{2}$, respectivamente, e a laje L3aR, com baixa taxa de armadura, rompeu com $3,25 \mathrm{kN} / \mathrm{m}^{2}$.

A Tabela 6 apresenta um sumário e comparações das principais características e cargas de ruptura das lajes L1, L3, L2R, L3aR e L4R. As lajes L1 e L3 (sem reforço) e as lajes L2R, L3aR e L4R (reforçadas) romperam por flexão apresentando grandes deslocamentos verticais e escoamento da armadura na face inferior, principalmente na região central. Em todos os testes, além do escoamento, houve a ruptura das barras centrais. Foi observado, após o término dos ensaios e a retirada do carregamento, que não havia indícios, na face superior, de esmagamento do concreto.

\begin{tabular}{c|c|c|c|c|c}
\hline \multicolumn{6}{|c}{ Tabela 5: Principais características do aço. } \\
\hline Laje & $\phi(\mathbf{m m})$ & $\mathbf{f}_{\mathrm{y}}(\mathbf{M P a})$ & $\varepsilon_{\mathrm{y}}(\%)$ & $\mathbf{f}_{\mathrm{u}}(\mathbf{M P a})$ & $\mathrm{E}_{\mathrm{s}}(\mathbf{G P a})$ \\
\hline $\mathrm{L} 1$ & 5,0 & 761,7 & 0,57 & 829,2 & 204,7 \\
\hline $\mathrm{L} 2$ & 5,0 & 734,2 & 0,56 & 771,6 & 200,3 \\
\hline L3 & 3,4 & 801,2 & 0,62 & 822,0 & 192,4 \\
\hline L3a & 3,4 & 759,2 & 0,57 & 780,6 & 205,2 \\
\hline L4 & 5,0 & 777,2 & 0,58 & 841,2 & 201,4 \\
\hline
\end{tabular}

Tabela 6: Sumário e comparações das principais características e cargas de ruptura das lajes L1, L3 e das lajes reforçadas L2R, L3aR e L4R.

\begin{tabular}{c|c|c|c|c|c|c|c|c} 
LAJE & $\mathbf{d}(\mathbf{c m})$ & $\boldsymbol{\rho}(\%)$ & $\mathbf{f}_{\mathbf{c}}(\mathbf{M P a})$ & $\mathbf{d}_{\mathrm{Li}} / \mathbf{d}_{\mathbf{L 1}}$ & $\rho_{\mathrm{Li}} / \rho_{\mathrm{L} 1}$ & $\mathbf{f}_{\mathrm{cLi}} / \mathbf{f}_{\mathrm{cL} 1}$ & $\begin{array}{c}\mathbf{q}_{\text {ruptura }} \\
\left(\mathbf{k N} / \mathbf{m}^{2}\right)\end{array}$ & $\mathbf{q}_{\mathrm{rup} \cdot \mathrm{Li}} / \mathbf{q}_{\mathrm{rup} \cdot \mathrm{L1}}$ \\
\hline $\mathbf{L 1}$ & 7,1 & 0,14 & 20,8 & 1,00 & 1,00 & 1,00 & 9,25 & 1,00 \\
\hline $\mathbf{L 3}$ & 6,0 & 0,07 & 20,4 & 0,86 & 0,50 & 0,98 & 3,00 & 0,32 \\
\hline L2R & $10,2^{*}$ & 0,09 & 51,9 & 1,43 & 0,64 & 2,49 & 12,25 & 1,32 \\
\hline L3aR & $10,5^{*}$ & 0,04 & 58,2 & 1,48 & 0,28 & 2,80 & 3.25 & 0,35 \\
\hline L4R & $10,0^{*}$ & 0,10 & 56,4 & 1,41 & 0,71 & 2,71 & 12,00 & 1,30 \\
\hline
\end{tabular}

$\mathrm{d}=$ Altura útil da laje;

${ }^{*} \mathrm{~d}_{\text {máx }}=$ altura útil da laje medida na região central reforçada;

$\rho=$ taxa de armadura de flexão;

$q_{\text {ruptura }}=$ Carga uniformemente distribuída de ruptura da laje. 
Pode-se observar, em relação à laje de referência, L1, que as lajes reforçadas $L 2 R$ e $L 4 R$ apresentaram cargas de ruptura superiores em 32 e $30 \%$ respectivamente. As lajes L3 e L3aR apresentaram cargas de ruptura significativamente inferiores quando comparadas com a laje de referência, L1. A laje L3 com resistência à compressão do concreto similar, e altura útil apenas $14 \%$ inferior, mas com uma taxa de armadura $50 \%$ menor que a da laje L1, rompeu por flexão com um carregamento $68 \%$ menor do que a laje de referência, L1.

Com relação às lajes $L 2 R$ e $L 4 R$, comparadas com a laje de referência $L 1$, pode-se notar, por um lado, uma redução na taxa geométrica de armadura (de 0,14 \% na L1 para 0,09 \% e 0,10 \% nas lajes $L 2 R$ e $L 4 R$, respectivamente), e por outro lado, um incremento da resistência do concreto (de 20,8 $\mathrm{MPa}$ na L1 para 51,9 MPa e 56,4 MPa nas lajes L2R e L4R, respectivamente) e principalmente um aumento na altura útil (de $7,2 \mathrm{~cm}$ na L1 para $10,2 \mathrm{~cm}$ e $10,0 \mathrm{~cm}$ na $L 2 R$ e L4R, respectivamente). $\mathrm{O}$ aumento da altura útil neste caso foi preponderante no ganho de $32 \%$ e $30 \%$ das cargas de ruptura das lajes $L 2 R$ e $L 4 R$, respectivamente, em relação à laje $L 1$.

A laje L3aR, comparada com a laje de referência, L1, apresenta uma altura útil $48 \%$ maior, uma resistência à compressão do concreto na camada de reforço de 2,8 vezes superior e por outro lado com uma taxa de armadura inferior que a laje $L 1$, rompeu com apenas 35 \% da carga de ruptura da laje L1, mesmo com a aplicação da camada de concreto do reforço. Este resultado mostra que o aumento da altura útil e o aumento da resistência à compressão do concreto na camada de reforço sem a devida existência de uma taxa mínima de armadura de flexão pode acarretar em um reforço inócuo.

Uma comparação entre as lajes reforçadas L2R e L4R corrobora a importância da altura útil (d) como parâmetro mais importante na determinação da carga última das lajes reforçadas, para lajes com taxas de armadura similares $(0,09 \%$ e 0,10 \% respectivamente). Apesar da laje L4, base da L4R, ter sido confeccionada com concreto de baixa resistência $\left(f_{c}=12,4 \mathrm{MPa}\right)$, cerca de $60 \%$ menor que o da laje L2 (20,7 MPa), o comportamento na ruptura foi bastante semelhante, carga última de $12,25 \mathrm{kN} / \mathrm{m}^{2}$ para a laje $L 2 R$ e de 12,0 $\mathrm{kN} / \mathrm{m}^{2}$ para a laje L4R denotando a pouca ou nenhuma influência do concreto da zona tracionada na capacidade de carga de ruptura da laje reforçada. Ressalte-se que as lajes L2 e L4 apresentaram comportamentos distintos durante o ensaio inicial até a carga de parada.

As primeiras fissuras observadas visualmente nas lajes L1 e L2 ocorreram com cargas de $2,50 \mathrm{kN} / \mathrm{m}^{2}$ e $2,25 \mathrm{kN} / \mathrm{m}^{2}$, respectivamente. Nas lajes $\mathrm{L} 3, \mathrm{~L} 3 \mathrm{a}$, com baixa taxa de armadura, e L4, com pequena resistência à compressão do concreto, as primeiras fissuras foram observadas com cargas de $1,25 \mathrm{kN} / \mathrm{m}^{2}$ (L3) e $1,0 \mathrm{kN} / \mathrm{m}^{2}$
(L3a e L4). As primeiras fissuras apareceram na região central em direção aos cantos. Em estágios avançados de carregamento ficam nitidamente definidas quatro áreas com as linhas de ruptura passando pelo centro em direção aos cantos. A Figura 7 mostra um esquema de fissuração da laje L1.

A Figura 8 apresenta um gráfico de carga versus deflexão central de todas as lajes. Em todas as lajes houve um aumento das flechas em função do acréscimo do carregamento. A laje L1, com altura efetiva igual a 7,1 $\mathrm{cm}$, apresentou a maior flecha central entre todas as lajes, atingindo $12,5 \mathrm{~cm}$ para um carregamento de ruptura de $9,25 \mathrm{kN} / \mathrm{m}^{2}$. Com exceção da laje $\mathrm{L3}$, os valores das flechas centrais das demais lajes não reforçadas variaram de $6,5 \mathrm{~cm}$ ( $(\mathrm{B} 3 \mathrm{a}, \mathrm{d}=6,0 \mathrm{~cm})$ a $7,5 \mathrm{~cm}$ $(\mathrm{L} 2, \mathrm{~d}=6,3 \mathrm{~cm})$, com cargas de parada de $2,25 \mathrm{kN} / \mathrm{m}^{2} \mathrm{e}$ $6,50 \mathrm{kN} / \mathrm{m}^{2}$, respectivamente. A laje $\mathrm{L} 3$, que rompeu com $3,0 \mathrm{kN} / \mathrm{m}^{2}$ apresentou uma flecha central medida de 6,4 $\mathrm{cm}$ para uma carga de $2,75 \mathrm{kN} / \mathrm{m}^{2}$.

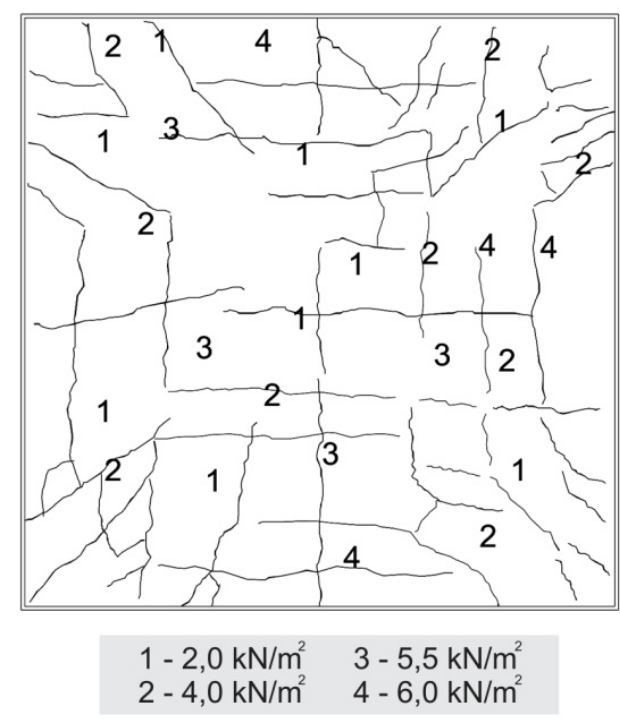

Figura 7: Esquema de fissuração da laje L1.

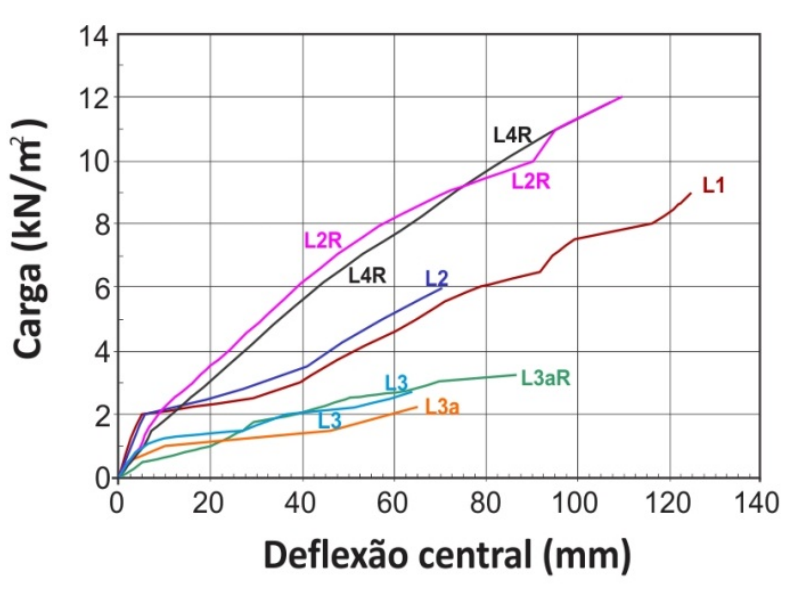

Figura 8: Gráfico de carga versus deflexão central de todas as lajes. 
As lajes reforçadas $L 2 R(d=10,3 \mathrm{~cm})$ e $L 4 R$ $(d=10,0 \mathrm{~cm})$ tiveram, na ruptura, flechas de $11,0 \mathrm{~cm}$ e $9,5 \mathrm{~cm}$, respectivamente, enquanto que a laje $\mathrm{L} 3 \mathrm{aR}(\mathrm{d}=$ $10,5 \mathrm{~cm}$ ) rompeu com uma flecha de $6,9 \mathrm{~cm}$. Pode-se observar que aquelas confeccionadas com deficiência de armadura, L3 e L3a, e a laje reforçada, L3aR, apresentam os maiores deslocamentos com as menores cargas. Um segundo grupo com as lajes L1 e L2, sem deficiências de armadura e do concreto, e a L4, com deficiência do concreto, apresentam, para os mesmos carregamentos, deslocamentos em uma mesma ordem de grandeza e com valores intermediários quando comparados com as demais lajes. No terceiro grupo, as lajes reforçadas $L 2 R$ e L4R, com comportamentos similares entre si, apresentam os menores deslocamentos para cargas maiores de $2,0 \mathrm{kN} / \mathrm{m}^{2}$. Estes menores deslocamentos, provavelmente ocorrem devido ao aumento da altura útil com a aplicação do concreto da camada de reforço. A laje L3aR, também com camada de reforço similar, não apresentou o mesmo perfil de deslocamento, provavelmente devido ao fato de ter sido confeccionada com deficiência da armadura de flexão.

A Tabela 7 apresenta um sumário dos resultados das flechas centrais de todas as lajes para cargas de $1,5 \mathrm{kN} / \mathrm{m}^{2}, 3,0 \mathrm{kN} / \mathrm{m}^{2}$, carga de parada (variável para cada laje) e carga da última leitura antes da ruptura. As lajes L1 e L2, com taxas de armaduras de acordo com a norma, atendem aos requisitos da NBR $6118 / 80$ quanto a flechas máximas admissíveis. As lajes, L3 e L3a, com deficiência de armadura, e a laje L4, com deficiência na resistência do concreto, alcançam, para carregamentos de $1,5 \mathrm{kN} / \mathrm{m}^{2}$ (de projeto), flechas superiores ao limite de norma $(1 / 500=8,0 \mathrm{~mm})$.

Ao se considerar apenas as lajes L1, L3 e L3a, com valores similares da resistência do concreto e da altura útil, pode-se perceber que a laje L1 com uma taxa de armadura igual a 0,14\%, apresentou uma flecha, para o carregamento de $1,5 \mathrm{kN} / \mathrm{m}^{2}$, de apenas $3,2 \mathrm{~mm}$, menos da metade do valor limite imposto por norma (NBR $6118 / 80)$, enquanto que as lajes L3 ( $\rho=0,07 \%)$ e L3a ( $\rho$ $=0,08 \%$ ), com $50 \%$ de armadura da laje L1, apresentaram flechas de 8 a 14 vezes maiores.

A laje L3aR, com a camada do concreto de reforço conduzindo por um lado a uma nova altura útil maior $(d=10,5 \mathrm{~cm}$ ) e uma resistência do concreto na região comprimida bastante superior $\left(f_{c}=58,2 \mathrm{MPa}\right)$, e por outro lado com uma taxa geométrica inferior, apresentou valores de flechas na mesma ordem de grandeza das lajes L3 e L3a, denotando a importância de uma taxa de armadura mínima no controle da flecha, independentemente do reforço.

\begin{tabular}{|c|c|c|c|c|c|c|c|c|c|c|c|c|}
\hline Laje & $\begin{array}{c}\rho \\
(\%)\end{array}$ & $\begin{array}{c}\text { d } \\
\mathrm{mm}\end{array}$ & $\begin{array}{c}\mathbf{f}_{\mathrm{c}} \\
\mathrm{MPa}\end{array}$ & $\begin{array}{c}q \\
k N / m^{2}\end{array}$ & $\begin{array}{c}\text { Flecha } \\
\mathrm{mm}\end{array}$ & $\begin{array}{c}q \\
k N / m^{2}\end{array}$ & $\begin{array}{c}\text { Flecha } \\
\mathrm{mm}\end{array}$ & $\begin{array}{c}q_{\text {parada }} \\
\mathrm{kN} / \mathrm{m}^{2}\end{array}$ & $\begin{array}{c}\text { Flecha } \\
\mathrm{mm}\end{array}$ & $\begin{array}{c}q_{\text {últ. leitura }} \\
\mathrm{kN} / \mathrm{m}^{2}\end{array}$ & $\begin{array}{c}\text { Flecha } \\
\mathrm{mm}\end{array}$ & $\begin{array}{l}q_{\text {ruptura }} \\
k N / m^{2}\end{array}$ \\
\hline L1 & 0,14 & 7,1 & 20,8 & 1,50 & 3,2 & 3,00 & 39,4 & --- & --- & 9,00 & 124,7 & 9,25 \\
\hline L2 & 0,15 & 6,2 & 20,7 & 1,50 & 4,0 & 3,00 & 31,3 & 6,50 & 62,3 & --- & --- & --- \\
\hline L2R & 0,09 & 10,2 & 51,9 & 1,50 & 6,1 & 3,00 & 16,0 & --- & --- & 12,00 & 109,6 & 12,25 \\
\hline L3 & 0,07 & 6,0 & 20,4 & 1,50 & 26,1 & 3,00 & --- & --- & --- & 2,75 & 64,0 & 3,00 \\
\hline L3a & 0,08 & 6,5 & 19,8 & 1,50 & 46,1 & 3,00 & --- & 2,25 & 65,2 & --- & --- & --- \\
\hline L3aR & 0,04 & 10,5 & 58,2 & 1,50 & 27,0 & 3,00 & 62,0 & --- & --- & 3,25 & 65,2 & 3,25 \\
\hline L4 & 0,16 & 6,0 & 12,4 & 1,50 & 13,7 & 3,00 & 46,6 & 4,75 & 69,8 & --- & --- & --- \\
\hline L4R & 0,10 & 10,0 & 56,4 & 1,50 & 7,2 & 3,00 & 19,6 & --- & --- & 11,00 & 95,4 & 12,00 \\
\hline
\end{tabular}

$\rho(\%)=$ taxa de armadura de flexão; $\mathrm{q}\left(\mathrm{kN} / \mathrm{m}^{2}\right)=$ carga distribuída aplicada;

qúlt. leitura $\left(\mathrm{kN} / \mathrm{m}^{2}\right)=$ carga distribuída aplicada correspondente à última leitura. 
Uma comparação entre as flechas centrais das lajes L1 ( $\left.f_{c}=20,8 \mathrm{MPa}\right)$ e L4 ( $f_{c}=12,4 \mathrm{MPa}$ ) evidencia a influência da resistência à compressão do concreto no comportamento dos deslocamentos verticais centrais. Uma redução de $60 \%$ da resistência à compressão do concreto acarretou flechas 4,3 vezes maiores para um carregamento de $1,5 \mathrm{kN} / \mathrm{m}^{2}$ e de apenas $18 \%$ maior para a carga de $3 \mathrm{kN} / \mathrm{m}^{2}$, indicando, provavelmente um aparecimento precoce de fissuras na laje de menor resistência. A laje L4R apesar de apresentar uma flecha maior do que a da laje $\mathrm{L} 1$ e menor do que a da laje L4, para um carregamento de $1,5 \mathrm{kN} / \mathrm{m}^{2}$, apresenta flechas consideravelmente menores do que as destas lajes para maiores carregamentos, demonstrando que o aumento da altura útil provocado pela camada de reforço supera, em estágios avançados de carga, a perda devida a influência da resistência à compressão do concreto. As lajes reforçadas aumentaram o limite de carregamento
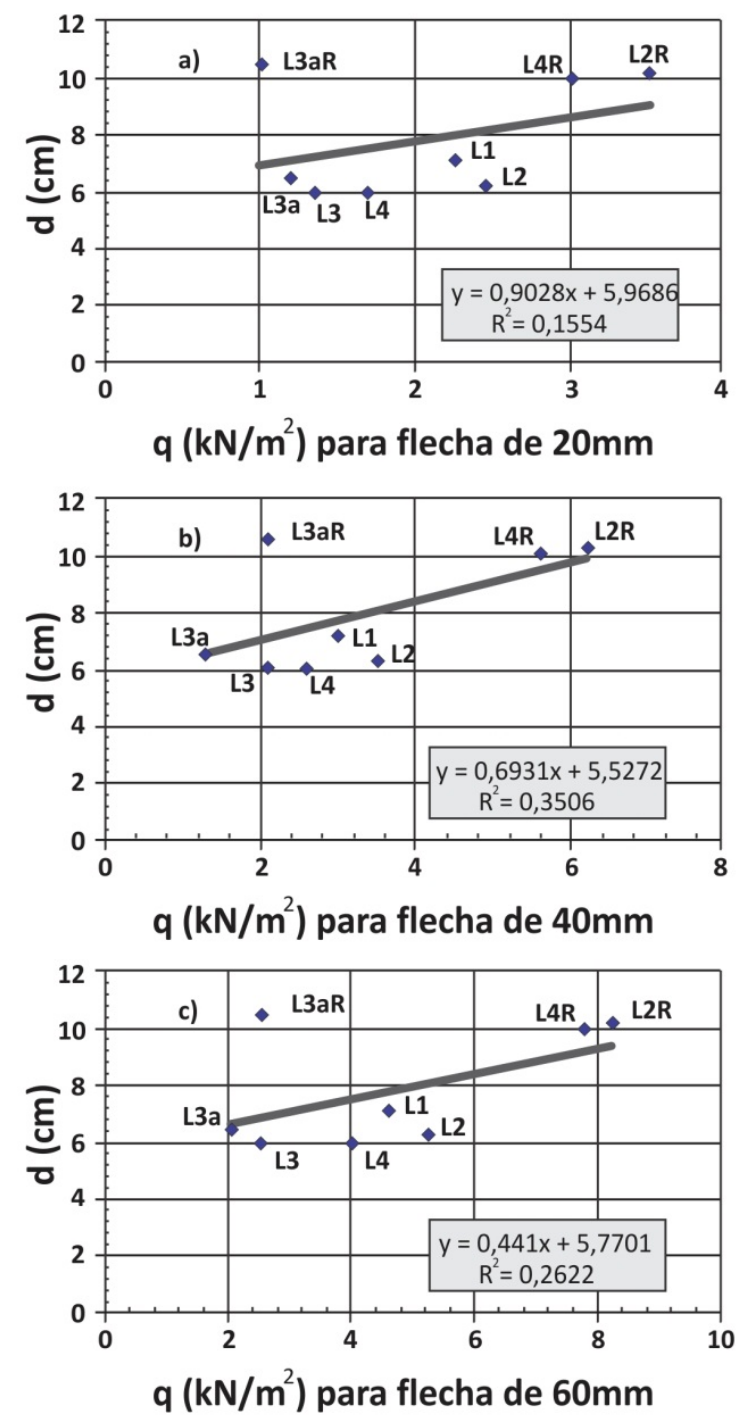

em relação ao carregamento final, mas este fato não alterou a flecha nos carregamentos iniciais, provavelmente devido ao estado de fissuração e deformação do aço provocado pelo ensaio inicial.

A Figura 9 apresenta seis gráficos da altura útil (d) versus carga para flechas de $20 \mathrm{~mm}, 40 \mathrm{~mm}$ e 60 $\mathrm{mm}$, para todas as lajes, com as equações e linhas de tendência e os respectivos valores de correlação $\left(R^{2}\right)$. A decisão de se comparar flechas superiores a de projeto se justifica devido à situação de reforço. Os gráficos "a", "b" e "c" da Figura 9 foram feitos considerando os dados de todas as lajes e apresentam baixos valores de correlação, $R^{2}$, inferiores a 0,36 , indicando uma dispersão considerável dos dados no ajuste da equação da reta, enquanto que os gráficos " $d$ ", " $e$ " e "f" foram construídos eliminando-se apenas os valores da laje L3aR e apresentam valores de correlação, $R^{2}$, superiores a 0,74 , indicando uma dispersão menor.
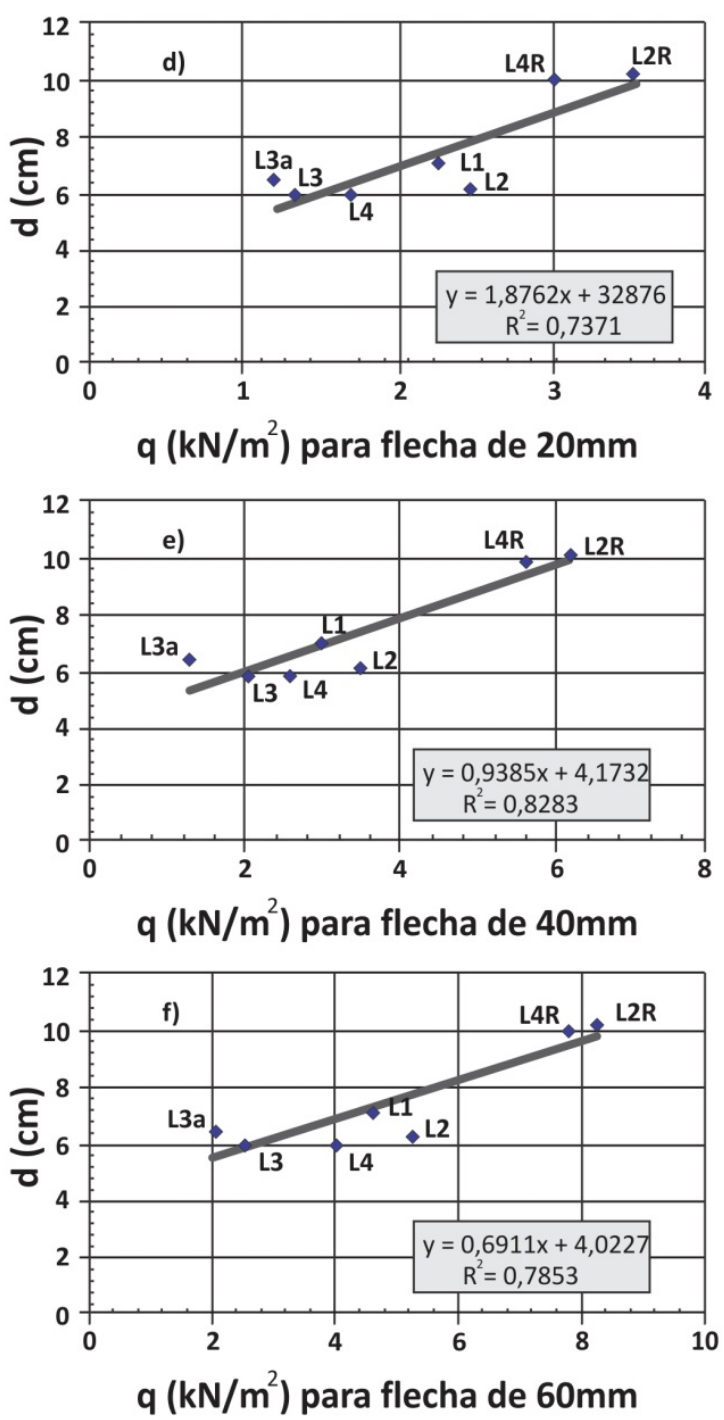

Figura 9: Gráficos da altura útil (d) versus carga para flechas de $20 \mathrm{~mm}, 40 \mathrm{~mm}$ e $60 \mathrm{~mm}$, para todas as lajes, com as equações e linhas de tendência e os respectivos valores de correlação $\left(R^{2}\right)$. 
Estes gráficos ressaltam relativa uniformidade de comportamento entre todas as lajes excetuando-se a L3aR, para cargas acima das de projeto. Observa-se que a laje L3aR, com a altura útil de $10,5 \mathrm{~cm}$ deveria ter a capacidade de absorver carregamentos da ordem de 3,5 $\mathrm{kN} / \mathrm{m}^{2}, 6,5 \mathrm{kN} / \mathrm{m}^{2}$ e $8,5 \mathrm{kN} / \mathrm{m}^{2}$ para flechas de $20 \mathrm{~mm}, 40$ $\mathrm{mm}$ e $60 \mathrm{~mm}$, respectivamente, caso seguisse a tendência das demais. Isto não ocorre, provavelmente, devido à baixíssima taxa de armadura (0,04\%) existente na laje $L 3 a R$, comparado com as demais lajes $(0,07 \%<\rho$ $<0,16 \%)$. Este resultado pode estar configurando um limite para o uso de reforço pela face superior em lajes que venham apresentar, após o reforço, uma taxa geométrica de armadura inferior a 0,07\%.

As medidas de deformações no aço obtidas através de extensômetros elétricos colados nas armaduras são apresentadas para cada laje ensaiada, exceto para as lajes reforçadas, pois no ensaio inicial os extensômetros foram solicitados e muitos se romperam durante os carregamentos até parada do ensaio. Para as lajes L1 e L2 utilizou-se dois extensômetros por ponto, um na face superior outro na inferior da barra instrumentada. As demais lajes, L3, L3a e L4, foram instrumentadas com apenas um extensômetro por ponto. As Figuras 10, 11 e 12 apresentam os gráficos de cargas versus deformações das armaduras das lajes L1, L2 e L3 respectivamente, até o carregamento de ruptura (L1 e L3) ou de parada (L2). Os extensômetros centrais apresentaram deformações equivalentes às de escoamento das barras como na laje L3.

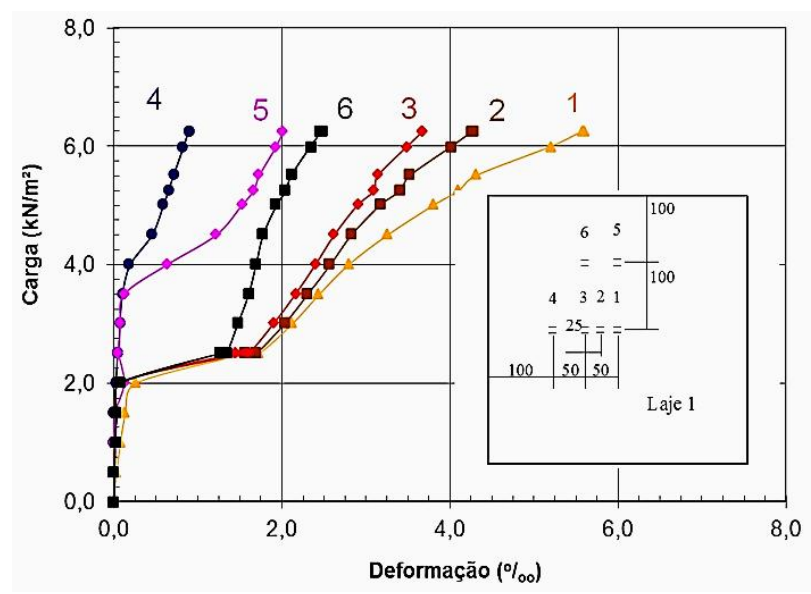

Figura 10: Gráfico de cargas versus deformações das armaduras das lajes L1.

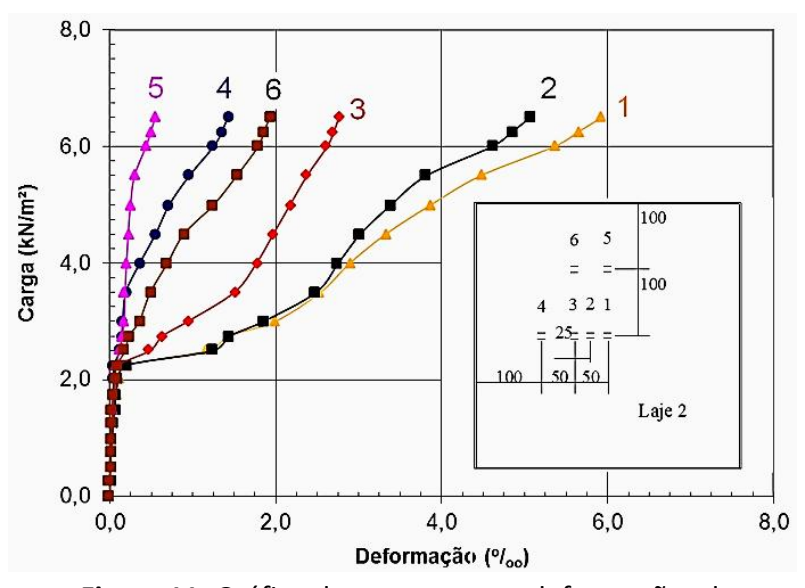

Figura 11: Gráfico de cargas versus deformações das armaduras das lajes $L 2$.

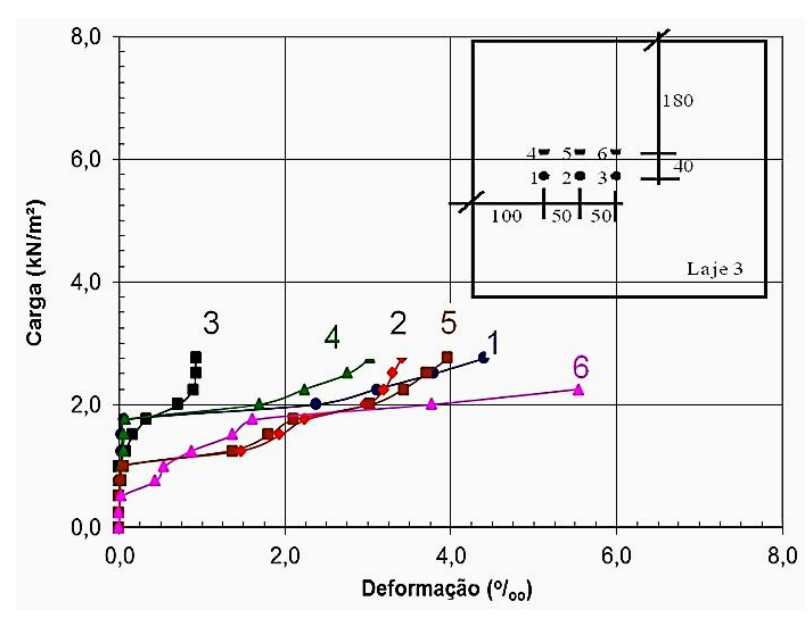

Figura 12: Gráfico de cargas versus deformações das armaduras das lajes L3.

\section{CONSIDERAÇÕES FINAIS}

O objetivo de verificar o comportamento estrutural de lajes reforçadas pela face superior com a adição de uma camada, na forma de lente, com concreto de alto desempenho, se mostrou eficaz para os casos em que havia uma taxa mínima de armadura $(0,07 \%$ no caso deste trabalho e $0,10 \%$ pela NBR $6118 / 80)$. Os resultados também mostram que as cargas últimas de ruptura podem ser estimadas com a utilização da altura útil da seção total, com a execução da camada de reforço, considerando o reforço trabalhando monoliticamente com a laje original.

Nas lajes armadas originalmente com uma taxa mínima de armadura, segundo a NBR 6118/80, a aplicação da camada de reforço elevou em até $30 \%$ a carga última de ruptura, em relação a uma laje similar sem reforço, (lajes L2R e L4R). Nas lajes com insuficiência de armadura, executadas com uma taxa de armadura no valor da metade do mínimo de norma, o reforço, apesar de elevar a carga última de ruptura, não demonstra o mesmo grau de eficiência, pois é limitada obviamente pela quantidade de armadura (laje L3a). 
Este limite de eficácia do reforço pela face superior em função da quantidade de armadura pode simbolizar alguns casos de viabilidade ou não da execução do reforço de lajes por este processo. Todas as lajes ensaiadas, reforçadas ou não, apresentaram grande ductilidade até a ruptura, com flechas maiores que a altura útil, entretanto tiveram uma ruptura brusca no final com o rompimento da armadura na região central.

As lajes com armadura mínima de norma, quando reforçadas apresentam menores flechas para carregamentos acima das cargas de projeto ou do aparecimento da primeira fissura. Já as lajes com deficiência de armadura, mesmo quando reforçadas, apresentaram sempre grandes deslocamentos. As lajes L1 e L2, com taxas de armaduras de acordo com a norma, atendem aos requisitos da NBR 6118/80 quanto a flechas máximas admissíveis. As lajes, L3 e L3a, com deficiência de armadura e a laje L4, com deficiência na resistência do concreto, atingem, para cargas de 1,5 $\mathrm{kN} / \mathrm{m}^{2}$ (de projeto), flechas superiores ao limite de norma de I/500 (8,0 mm). As lajes reforçadas L2R, L3aR e L4R apresentaram flechas no mínimo de 30\% inferiores, para o mesmo carregamento de parada das respectivas lajes não reforçadas, denotando a eficiência do reforço quanto ao deslocamento vertical central.

\section{AGRADECIMENTOS}

A Realmix, a Impercia S.A e a Carlos Campos Consultoria Limitada que disponibilizaram parte dos materiais utilizados e pela ajuda na caracterização do concreto. Ao CNPq e o Procad - Programa de cooperação acadêmica da Capes pelo apoio institucional.

\section{REFERÊNCIAS BIBLIOGRÁFICAS}

AGOPYAN, V. Ary Torres e a tecnologia do concreto. Revista Politécnica, número 208, jan. / abr., 1993, p. 39.

AIDAR, J. L. e CYTRYNOWICZ, A. Tradição de ensino no rumo da tecnologia do século 21. Revista Politécnica, número 208, jan. / abr., 1993, p.16 -18.

ASSOCIAÇÃO BRASILEIRA DE NORMAS TÉCNICAS NBR 6118 - Projeto e execução de obras de concreto armado. Rio de Janeiro, 1980, 63 p.

Boletim do Laboratório de Ensaios e Materiais, número 1, Escola Politécnica de São Paulo, EPUSP, 1933.

CAMPOS, C. O., Análise experimental de lajes de concreto armado reforçadas pela face superior. Tese (Mestrado em Engenharia Civil) - Escola de Engenharia Civil, Universidade Federal de Goiás, Goiânia, Setembro, 2000, $131 \mathrm{p}$.
Revista Dirigente Construtor, Vol. XXII, no 5, Concreto, cresce a participação do projetado, maio, 1987.

SOUZA, V. C. M e RIPPER, T. Patologia, Recuperação e Reforço de estruturas de concreto. São Paulo, Editora PINI, 1a Edição, 1998, 255 p. 